\title{
The role of Salvelinus in contemporary studies of evolution, trophic ecology and anthropogenic change
}

\author{
Rune Knudsen • Anders Klemetsen • Sergey Alekseyev • \\ Colin E. Adams • Michael Power
}

Received: 29 August 2016/Revised: 16 September 2016/Accepted: 23 September 2016/Published online: 5 October 2016

(C) Springer International Publishing Switzerland 2016

The first international symposium on Arctic charr (Salvelinus alpinus) was held in May, 1981, in Winnipeg, Manitoba, Canada, following shortly after the release of the seminal publication Charrs: Salmonid Fishes of the Genus Salvelinus (Balon, 1980), and sought to bring together scientists from nations in the circumpolar region containing Arctic charr or its close relatives in the $S$. alpinus complex. Since then, symposia have been held in Japan (1988), Norway

Guest editors: M. Power, R. Knudsen, C. E. Adams, M. J. Hansen, J. B. Dempson, M. Jobling \& M. Ferguson / Advances in Charr Ecology and Evolution

R. Knudsen · A. Klemetsen

Department of Arctic and Marine Biology, Faculty of Biosciences, Fisheries and Economics, UiT The Arctic University of Norway, 9037 Troms $\varnothing$, Norway

\section{S. Alekseyev}

Kolzov Institute of Developmental Biology, Russian

Academy of Science, Moscow, Russia

C. E. Adams

Scottish Centre for Ecology \& the Natural Environment, University of Glasgow, Rowardennan, Glasgow,

Scotland G63 0AW, UK

\section{Power ( $₫)$}

Department of Biology, University of Waterloo, 200

University Avenue West, Waterloo, ON N2L 3G1,

Canada

e-mail: m3power@sciborg.uwaterloo.ca
(1994), Canada (2000), Iceland (2006), Scotland (2009) and Russia (2012). On the 14th June 2015, reflecting a buoyant research interest in Salvelinus, 112 participants from 13 countries gathered for the 8th International Charr Symposium in Troms $\varnothing$, Norway. Hosted by the UiT, The Arctic University of Norway, delegates included: 9 from Russia, 13 from USA, 15 from Canada, 9 from Japan, 8 from Iceland, 6 from Sweden, 3 from Scotland, 2 from Finland, 1 each from France, The Netherlands, Switzerland and Spain and 43 from Norway. In total, there were 79 oral presentations and 28 posters presented over the 4 days of meetings. Topical themes covered by the presentations and posters included anadromy, aquaculture, climate change, ecology, evolution, genetics, fisheries management, life history, parasitology and pollution impacts.

Although the majority (two-thirds) of studies presented at the symposium focused on Arctic charr, there were many devoted to Dolly Varden charr (Salvelinus malma), Lake charr (Salvelinus namaycush), Brook charr (Salvelinus fontinalis) and Whitespotted charr (Salvelinus leucomaenis). The contributions covered two major geographic areas: northern Europe, and the Pacific basin drainages of the Asian and North American coasts. The vast area comprising the range of Salvelinus between these two more highly investigated regions was represented by only a few presentations from the Kola Peninsula, Siberia and Greenland, with the geographic spread of studies 
clearly demonstrating the need for more extensive Salvelinus research in the less investigated areas.

Over the intervening period since the first Charr Symposium, tools for addressing research questions of interest have evolved, most notably with advances in genetics, statistics and the application of microchemical analyses, such as stable isotopes. Nevertheless, many of the questions that were being asked in the last century remain relevant to charr biologists today. How did charrs evolve and what controlled the rate of evolution? What explains the diversity found among charrs and what is its evolutionary significance? Why do we appear to see greater divergence in some Salvelinus species, e.g. S. alpinus and S. malma, than others, e.g. S. leucomaenis? What is the importance of life-history variation and what controls it? Crucially, new methods for linking genotype to phenotype (genomics, transcriptomics and micro RNA analysis) were used in several studies to reveal a genetic basis for morphological traits in natural populations and open a new direction for the future study of Salvelinus ecology, evolution and development.

The initial collection of published papers emanating from the charr symposium series was almost exclusively focused on a single species, Arctic charr. Subsequent symposia and associated publications, however, have become considerably more varied over the years and now include considerations of all aspects of the biology, ecology, physiology and husbandry of fishes in the genus Salvelinus. The diversification in interest has been accompanied by exponential growth in the number of scientific publications devoted to Salvelinus, particularly in the period leading up to 2000 (Fig. 1). Scientific publications on the genus Salvelinus now average some 300 a year, with a third of those being accounted for by Arctic charr. In that regard Salvelinus remains an important model group of fish species with which to explore fundamental evolutionary and ecological questions.

No less diverse were the series of papers given at the eighth symposium in Norway, a diversity that is reflected in the associated collection of papers reviewed and accepted for publication as part of the symposium proceedings that follow. The papers may be roughly grouped into three topic groups: lifehistory and trophic ecology, evolutionary studies and studies of the effects of human interactions with charr, e.g. contaminant impacts. While themes related to the

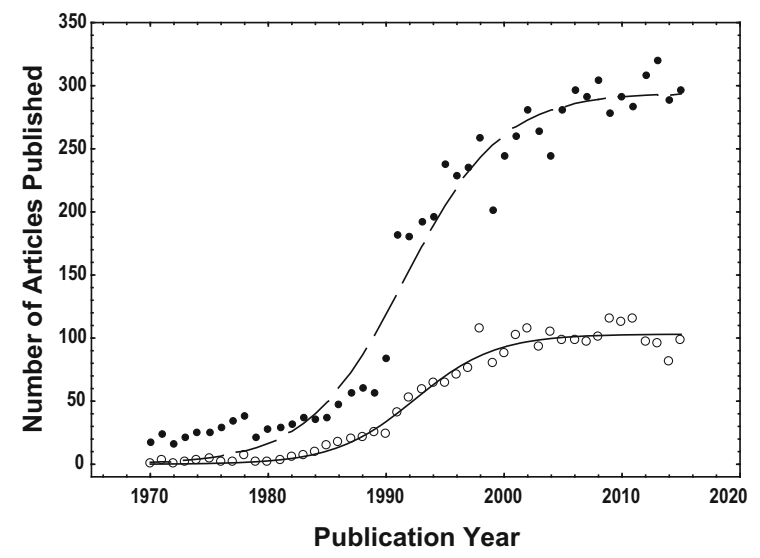

Fig. 1 Growth in the number of scientific papers published 1970-2015 as cited in the Web of Science. The top curve traces the growth of papers reported by publication year using the search term "Salvelinus". The bottom curve traces the growth of papers reported by publication year using the more restrictive search term "Salvelinus alpinus". Growth in the number of papers published is described by a logistic growth curve in both instances (all parameter $P \leq 0.001, r^{2} \geq 0.989$ )

life-history and evolutionary ecology of species have remained more or less constant in terms of emphasis, interests and emphasis on the impacts of human activity on charrs have grown in importance. To some extent the grouping is arbitrary, given the multidisciplinary approaches used by most investigators, but each reflects a current emphasis within the research community on questions of interest as they pertain to Salvelinus populations. The development of laboratory methods and the recent rapid decline in analytical costs associated with the completion of laboratory testing has facilitated multi-disciplinary approaches to the study of charrs; a trend that will undoubtedly both increase in the future and provide novel insights into Salvelinus biology.

\section{Life-history and trophic studies}

Salvelinus, and especially Arctic charr, appear to be vulnerable to climatic changes and other anthropogenic disturbances (e.g. Reist et al., 2006, 2013; Jeppesen et al., 2012). Recently, there has been a focus on anthropogenic contamination in Arctic environments, specifically related to bio-magnification of mercury as a problem in non-industrialized highlatitude areas (e.g. van der Velden et al., 2013, 2015). 
The total mercury $(\mathrm{THg})$ concentrations in Arctic charr tissues seem to be altered by their seasonal shift in diet from benthos (winter) to a dominance of zooplankton (late summer and autumn), as was confirmed using stable isotope studies in a north Norwegian lake (Kahilainen et al., 2016b). The THg concentrations in Arctic charr in the subarctic Lake Galggojavri were low, and no individuals exceeded the recommended health authorization limits (Kahilainen et al., 2016b). As the month when fish were collected was an important explanatory factor for $\mathrm{THg}$ concentration, seasonality should be considered when designing future mercury (and/or other pollutants) monitoring programmes. No less important are considerations of life history, as studies with Dolly Varden charr from the Canadian Arctic have demonstrated (Tran et al., 2016). Significant differences in $\mathrm{THg}$ were found between resident and anadromous forms. In contrast to other northern anadromous fish species, e.g. Arctic charr, THg concentrations were higher in the anadromous Dolly Varden life-history types, although standardization for common age indicated the reverse pattern. Feeding on more THgcontaminated marine prey from higher trophic levels and somatic growth dilution explained the pattern of absolute and standardized results, highlighting the importance of considering life-history variation when interpreting THg concentrations in fish.

Arctic charr are cold-water adapted (Power et al., 2008) and are probably the salmonid with the lowest tolerance to increased water temperatures (Elliott \& Elliott, 2010). It is therefore of concern that Arctic charr populations may be increasingly affected by large-scale ecological perturbations such as global warming that may lead to their extirpation at the southern edge of its distribution (Winfield et al., 2010; Finstad et al., 2011). Ironically for a notably plastic species, Arctic charr have a particularly narrow range of temperature preferences (Larsson et al., 2005; Siikavuopio et al., 2014) and competitive displacement by other species related to those narrow thermal tolerances may already be occurring. As Svenning et al. (2016) have shown from long-term studies in northern Norway, temperature changes can affect salmonids across a hierarchy of spatial and temporal scales such that shifts in river thermal regimes may influence interspecific interactions. Thus, in many northern Norwegian rivers, shifts in the relative abundance of competing salmonids appear to have been driven by temperature changes, with Atlantic salmon (Salmo salar) having displaced previously dominate Arctic charr to marginal, slow flowing bankside habitats. Associated with the displacement was a change in the relative growth rates of the two species, with Atlantic salmon growing relatively faster than Arctic charr as temperatures rose, a change with obvious consequences for relative species' abundances given the predominance of size-dependent fecundity in Arctic charr (Power et al., 2005).

The knowledge of basic Arctic charr biology, lifehistory traits, ecology and evolutionary processes is essential for scientific understanding and for the development of future management strategies for charrs, both for the adaptive management of native charrs and invading species and for the restoration of anthropogenic-affected populations where morphotype-specific restoration objectives may be needed (Hansen et al., 2016b). For example, White-spotted charr typically occupy the upstream reaches of Japanese streams, whereas masu salmon (Oncorhynchus masou) are generally found downstream, with velocity being an important determinant of the observed altitudinal distribution patterns of the two species (Morita et al., 2016). Understanding of velocity constraints on the distribution of fish within watersheds has immediate implications for decisions regarding river regulation, particularly as water is increasingly diverted for energy and other industrial uses (Sabater, 2008).

Anadromous riverine populations of Arctic charr and populations at the southern edge of the distribution also appear vulnerable to climate change given that their thermal refugia are expected to be truncated by interactions with co-existing or invading fish species. Juveniles of riverine anadromous Arctic charr show a clear food segregation with other fish species (Atlantic salmon and alpine bullhead, Cottus poecilopus) living in sympatry (Sánchez-Hernández et al., 2016). In competition with these other species Arctic charr showed the greatest capacity to forage at the water surface, eating mainly surface prey (terrestrial and emerged aquatic insects). In contrast, the other species consumed largely benthic resources. The vertical segregation may be important for coexistence of sympatric species, facilitating food resource partitioning (Sánchez-Hernández et al., 2016). Similarly, resource partitioning in food, space and time appears to dominate in other fish communities where Arctic 
charr are present. For example, in lake communities with Arctic charr and other resident fish species such as European whitefish (Coregonus lavaretus), perch (Perca fluviatilis), and Brown trout (Salmo trutta), Arctic charr appear to rely much less on littoral resources in large and deep southern Scandinavian lakes than in small, shallow northern Scandinavian lakes (Sandlund et al., 2016). The associated interspecific interactions with resident littoral and pelagic resource competitors can lead to niche compression, increasing the vulnerability of Arctic charr to other possible ecological disturbances, i.e. habitat alterations. While the high niche plasticity of Arctic charr seems essential for their coexistence with competitively superior fish species (Sandlund et al., 2016; Sánchez-Hernández et al., 2016), the adaptive ability of Arctic charr is not limitless.

Other ecological interactions, such as predation, may also have a profound effect on prey populations and fish community structure. In an allopatric Arctic charr population, the life-history trade-off between sexual maturation and somatic growth remained stable throughout a 12-year study (Amundsen, 2016). The subarctic lake was dominated by stunted charr (slow growth and early maturation) experiencing high intraspecific resource competition for limited food, but with some individuals becoming largebodied via delayed maturation and cannibalism. The contrasting life-history strategies appeared coupled with cannibalism and represent two apparently stable strategies (Amundsen, 2016). Interestingly, such long-term ecological stability could transform into evolutionary stable strategies, and thus cannibals could locally evolve into a specialized piscivore morph. Reproductively isolated piscivore morphs of Arctic charr are known from a few post-glacial lakes, but their ecology is comparatively less well explored than that of the more common benthivore-zooplanktivore polymorphism. The piscivore Arctic charr morph from the trimorphic subarctic Lake Skogsfjordvatn has evolved typical piscivore traits (i.e. large jaws, robust skulls) similarly seen among Brown trout that regularly become piscivorous (Knudsen et al., 2016b). In addition, the piscivorous morph was the main Arctic charr predator in the lake ecosystem and started to feed on fish at a smaller size and took larger prey relative to body length than the co-occurring trout (Knudsen et al., 2016a, b). Thus, predation may have a strong structuring effect on fish populations in subarctic lake ecosystems. Salvelinus seem well suited to study the effects from predation as piscivory among charrs ranges from cannibalism, via intraspecific predation, to highly piscivorous species such as Lake charr populations (Amundsen, 2016; Bryce et al., 2016; Hansen et al., 2016a, b; Knudsen et al., 2016b).

Parasitism is one of the traditional ecological interactions with effects likely to be reflected in host populations. The parasite communities of Arctic charr are fairly species rich (Kuhn et al., 2016; Siwertsson et al., 2016) and can act as model systems to study the effects of parasites on fish hosts. The parasite community of Arctic charr intestinal species studied over a two-decade period appeared stable (Kuhn et al., 2016). Interspecific interactions between the most commonly occurring intestinal parasites (e.g. trematodes, Crepidostomum spp., and adult cestodes, Eubothrium salvelini) appeared low, with any observed between-host variation being attributed to differences in the habitat and dietary choice of individual fish (Kuhn et al., 2016). Likewise, there were stable, parallel, and predictable structures of parasite communities in replicated polymorphic Arctic charr morphs among environmentally similar subarctic lakes (Siwertsson et al., 2016), with the small-sized deep-living (profundal) morph having less species and a lower abundance of parasites compared with the sympatric littoral spawning morph (Siwertsson et al., 2016). Thus, as most of the parasite species from subarctic lakes are transmitted via trophic interactions, the relatively stable trophic niches of mono- and polymorphic Arctic charr host populations through time and among lakes are likely to result in a similar stability within their associated parasite communities (Henriksen et al., 2016; Kuhn et al., 2016; Siwertsson et al., 2016).

The combined ecological effects from parasitism and predation are implied in several studies (Henriksen et al., 2016; Knudsen et al., 2016b; Siwertsson et al., 2016). Highly specialized piscivore morphs of Arctic charr evidently accumulate high densities of deleterious parasite species, such as Diphyllobothrium spp. cestode larvae, through their prey (Knudsen et al., 2016b; Siwertsson et al., 2016). Similarly, large-sized piscivorous Brown trout accumulate high densities of Diphyllobothrium spp. via their diet (Henriksen et al., 2016). In contrast, sympatric monomorphic Arctic charr acquire parasite larvae mainly through zooplankton-feeding as copepods serve as intermediate 
hosts (Henriksen et al., 2016). Thus, deleterious parasite species, e.g. larval Diphyllobothrium spp., may accumulate in a host as a result of its trophic behaviour and have profound ecological implications at the population level for the hosts (Curtis, 1984). The combined effects of parasitism and predation may have evolutionary as well as ecological consequences for charrs. However, compared with the role of competition, modest attention has been paid to how predation and/or parasite-mediated selection may promote the incipient speciation process causing reproductively isolated units (e.g. Karvonen \& Seehausen, 2012). The relative ubiquity of Arctic charr in essentially similar subarctic ecosystems suggests they are well suited for studying such evolutionary processes.

\section{Evolutionary studies}

One major advance in the study of evolutionary processes has been the very rapid development of new genomic tools that have the potential to provide novel insights that have not been possible in the past, for example, in the illustration of the degree of straying and the role it might play in determining contemporary genetic stability within populations (Santaquiteria et al., 2016). The very high-resolution approach that is now realistically possible through "next-generation sequencing" is starting to allow us to disentangle the patterns of phenotypic variation we see among Salvelinus populations in the wild at the genetic level (Elmer, 2016). In addition, new RNAseq techniques examine messenger RNA and are thus beginning to give us some ideas of which, how and when, genes are being expressed. Of particular relevance for those of us interested in Salvelinus spp. as evolutionary models is the insight we gain when closely related, recently divergent ecotypes differentially express genes (Elmer, 2016). It is not just the molecular techniques that have developed with time. Recent years have also seen significant strides through the emergence of new statistical techniques that are providing evolutionary insights not previously possible. The application of Bayesian modelling to selection neutral population markers, such as microsatellites, has allowed us to address new evolutionary questions to explain the patterns of divergence among populations in the wild. Præbel et al. (2016), for example, showed that the magnitude of a sympatric divergence of Arctic charr was greater at the genetic level than that of an allopatric divergence (of the same ancestor) using some of the newly developed statistical modelling techniques.

The high degree of phenotypic variation within the genus Salvelinus continues to provide a rich vein of productive research into the evolutionary process. The scale at which this variation is viewed provides contrasting and valuable perspectives. Taylor (2016) reviews the pattern across the Salvelinus genus from north-western North America, showing that there are three clear Salvelinus species within which subspecies and distinct morphological forms are found in sympatry. In contrast, Knudsen and colleagues use local scale patterns to compare apparently similar and parallel divergences in S. alpinus which exhibits as functionally similar morphs in sympatry in two northern Norwegian lakes (Knudsen et al., 2016a). Interestingly, in Scotland, Hooker et al. (2016) describe a previously unknown sympatric divergence in $S$. alpinus into profundal macrobenthos- and plankton-feeding specialists which closely mirrors that reported by Knudsen and his colleagues in Norway (Knudsen et al., 2016a). Bryce et al. (2016) test if the degree of divergence of characters with a strong functional significance (dentition and respiratory capacity features) among three $S$. alpinus morphs in sympatry is predicted by the timing of genetic separation of populations. Surprisingly, they find that between-morph divergences in the expression of these traits are not simply linked to the length of time since divergence among morphs, with trait differences having arisen equally quickly in a recent (in situ) divergence as they have in older, ex situ divergences.

A common approach to attempting to understand the evolutionary processes leading to a divergence of phenotypes so commonly described across the Salvelinus genus is to attempt to examine the consequences of differential phenotypic expression. Kahilainen et al. (2016a) contrast the visual pigments in the eyes of deep and shallow water-living morphs of Arctic charr and European whitefish, and showed significant differences between species that logically equate to differences in visual capacity under different light regimes. In contrast, Miyamoto (2016) investigated the effect of skin colouration on predation risk in White-spotted charr, contrasting risk with that of other related species. This work showed a clear functional link between colouration and predation risk. 
Salvelinus as a genus is known to show considerable phenotypic plasticity. It is frequently argued that this plasticity is one potential route through which the genus may be able to diverge so rapidly (Levis \& Pfennig, 2016).

Interestingly, many of the evolutionary presentations at the symposium addressed intra-lacustrine Salvelinus polymorphisms, its causes, and mechanisms of diversification in polymorphic populations. Of particular interest was the fascinating number of sympatric forms of S. alpinus from Lake Tinnsjøen in Norway (four, as in Lake Thingvallavatn in Iceland), with an exotic profundal form found at $450 \mathrm{~m}$ depth that parallels that reported in Gander Lake, Newfoundland, (O'Connell et al., 2005). Additional studies of intraspecific variation in Brook charr (Bertrand et al., 2008; Samways et al., 2015), Dolly Varden (Oleinik \& Skurikhinal, 2010), and Lake charr (Eshenroder, 2008; Chavarie et al., 2016) have similarly demonstrated the high degree of polymorphism observed in Arctic charr, such that one can conclude it to be characteristic of the genus Salvelinus.

\section{Human interaction studies}

Increasingly research is focusing on the consequences of anthropogenic activities for Salvelinus species as result of growing anthropogenic pressures on the ecosystems in which they are found. Ecosystems once thought to be pristine are more frequently being perturbed by human activities associated with industrial development that have resulted in polluted environments, increasing habitat destruction (e.g. through eutrophication), barriers to migration, overfishing, the introduction of alien species and, most recently, climate warming (Maitland, 1995). While climate change is typically thought to pose the greatest threat (Reist et al., 2006; Power et al., 2008), point source pollution and species introductions can equally have significant negative impacts on populations at local or regional scales. For example, Esin \& Fedosov (2016) noted that chronic pollution associated with volcanic mineral suspensions and dissolved metals pollution in rivers increased morphometric variability among juvenile Dolly Varden charr, suggesting that relatively routine morphological measurement could be used to estimate the effect of activities such as mining and ore processing on fish.
The introductions of non-native species have caused various negative impacts on native species and their ecosystems, with hybridizations among closely related species that can cause displacement or the disruption of a locally adapted gene complex being particularly prevalent (Fukui et al., 2016). Longterm study of ecosystems that remain relatively unperturbed after an introduction is required to understand the implications of hybridizations for resident populations. As Fukui et al. (2016) noted from studies in the upper Sorachi River, Hokkaido, Japan, hybridization of native White-spotted charr with introduced Brook trout has not lead to declines in the native species. Rather declines in the introduced species were reported, although results may have been confounded by other factors, including increasing competition from non-native Rainbow trout (Oncorhynchus mykiss) and climate-related mediation of species' distribution and abundances.

Complications posed for long-term study of ever changing conditions have led some to use simulation modelling as an approach to understanding both the consequences of species introductions and the potential for corrective management action. Non-native Lake trout displaced native Bull trout (S. confluentus) in Flathead Lake, Montana when Mysis diluviana became abundant following its introduction into the lake watershed. To understand the possible consequences of proposed management actions aimed at restoring native Bull trout populations, Hansen et al. (2016a) developed a simulation model to determine how increased fishing mortality on Lake trout might enable Bull trout recovery, noting that significant increases in fishing effort would be required to reduce Lake trout populations enough to effect the ecological release of Bull trout from Lake trout predation pressure. Modelling experiments such as these can provide useful descriptive data relating cause to effect. Given the complexity of ecosystems, simulation provides one of the few systematic means within which the dynamics of population-level responses to a suite of interacting anthropogenic and natural stimuli can be appropriately analysed (Minns, 1992). Accordingly, there is likely a substantial future for modelling approaches for addressing many of the Salvelinus species management-related questions, particularly as human impacts in populations continue to mount.

Short of exploitation studies (e.g. Dempson, 1995; Dempson et al., 2008; Gallagher \& Dick, 2010), there 
have been relatively few investigations focusing directly on human-charr interactions. The emergence of biotelemetry technologies has enabled researchers to document how undisturbed organisms interact with each other and their environment in real time (Cooke et al., 2004) and has great potential for applied research into human interactions with charrs. Recognizing the importance of gathering baseline information on human-charr interactions, Jensen et al. (2016) employed biotelemetry methods to better understand coastal habitat use by Arctic charr in north Norway and the distribution of fish with respect to physical environmental variables, e.g. temperature, and areas affected by human activity. The most heavily used areas were found to be those also influenced by human activities proximate to coastal settlements, with the availability of waters with appropriate temperatures likely being the key determinant of habitat occupancy.

Interest in the aquaculture of Salvelinus species has a long history, in part because of the eating quality of wild counterparts and the value of the end product for the restaurant trade. Initial interest focused on the mechanics of farming and tuning rearing conditions to the physiology of the fish. Increasingly, however, genetics has come to play a major role in aquaculture study, particularly as the role of selection is better understood and exploited. Thus, Sæther et al. (2016) examined the role that the known plasticity of Arctic charr might play in the adaptation of the species under aquaculture conditions and concluded that plasticity is both a strength and a weakness for the species in aquaculture systems. The capability of Arctic charr to express considerable variation in growth rate and age at sexual maturation is arguably disadvantageous to commercial culture. In contrast, the ability to survive in a wide range of salinities and the tolerance of a range of densities is a positive advantage.

\section{Conclusion}

The research contained in this compendium of studies from the eighth symposium is built upon the history of earlier work and presents a view of many of the questions being investigated by Salvelinus biologists toady. While the range of studies included is broad, the collection of studies cannot hope to cover the breadth of Salvelinus-related research currently being carried out. Nevertheless, the papers serve as a useful focal point for contemporary research that when contrasted with past symposia will allow readers to see how Salvelinus research has evolved in the intervening $30+$ years. The diversity displayed within and among charr species will undoubtedly continue to both challenge and delight charr researchers, making charrs suitable models for addressing a variety of the key questions facing evolutionary and ecological research as a whole: an improved understanding of the mechanisms giving rise to phenotypic and genotypic diversity, mechanisms driving speciation, the relative importance of ecological factors for determining within and among population diversity, and the vulnerability of ecosystem structure to large-scale anthropogenic-induced changes, e.g. climate change. Because Salvelinus are predominately distributed in north temperate, subarctic and Arctic environments, they will increasingly face pressure from growing human demands for the resources within what have been hitherto relatively undisturbed habitats. Thus, questions of conservation and management are likely to become ever more pressing and future Salvelinus research will need to answer critical issues with regard to the ecological resilience and resistance of the many species that make up the Salvelinus complex (e.g. Hammar, 2014). These challenges imply a busy immediate future for Salvelinus-related research and, without question, the need to report in future symposia proceedings on the novel insights gained from the ongoing study of fishes in the genus Salvelinus.

\section{References}

Amundsen, P.-A., 2016. Contrasting life-history strategies facilitated by cannibalism in a stunted Arctic charr population. Hydrobiologia. doi:10.1007/s10750-015-2600-y.

Balon, E. K. (ed.) 1980. Charrs: Salmonid Fishes of the Genus Salvelinus. W. Junk Publishers, The Hague: 928 pp.

Bertrand, M., D. J. Marcogliese \& P. Magnan, 2008. Trophic polymorphism in brook charr revealed by diet, parasites and morphometrics. Journal of Fish Biology 72: 555-572.

Bryce, C., A. Fraser, R. Knudsen, R. Greer \& C. E. Adams, 2016. Divergent functional traits in three sympatric Arctic charr Salvelinus alpinus morphs are not coupled with the age of the lineage divergence. Hydrobiologia. doi:10.1007/ s10750-016-2964-7.

Chavarie, L., K. Howland, P. Venturelli, B. C. Kissinger, R. Tallman \& W. Tonn, 2016. Life-history variation among four shallow-water morphotypes of lake trout from Great Bear Lake, Canada. Journal of Great Lakes Research 42: 193-203. 
Cooke, S. J., S. G. Hinch, M. Wikelski, R. D. Andrews, L. J. Kuchel, T. G. Wolcott \& P. J. Butler, 2004. Biotelemetry: a mechanistic approach to ecology. Trends in Ecology and Evolution 19: 334-343.

Curtis, M.A., 1984. Diphyllobothrium spp. and the Arctic charr: parasite acquisition and its effects on a lake-resident population. In Johnson, L., \& B. I. Burns (eds), Biology of the Arctic charr. Proceedings of the International Symposium on a Arctic charr, Winnipeg, Manitoba. Manitoba. University of Manitoba Press, Winnipeg, Manitoba: 395-411.

Dempson, J. B., 1995. Trends in population characteristics of an exploited anadromous Arctic charr, Salvelinus alpinus, stock in northern Labrador. Nordic Journal of Freshwater Research 71: 197-216.

Dempson, J. B., M. Shears, G. Furey \& M. Bloom, 2008. Resilience and stability of north Labrador Arctic charr, Salvelinus alpinus, subject to exploitation and environmental variability. Environmental Biology of Fishes 82: 57-67.

Elliott, J. M. \& J. A. Elliott, 2010. Temperature requirements of Atlantic salmon Salmo salar, brown trout Salmo trutta and Arctic charr Salvelinus alpinus: predicting the effects of climate change. Journal of Fish Biology 77: 1793-1817.

Elmer, K. R., 2016. Genomic tools for new insights to variation, adaptation, and evolution in the salmonid fishes: a perspective for charr. Hydrobiologia. doi:10.1007/s10750015-2614-5.

Eshenroder, R. L., 2008. Differentiation of deep-water lake charr Salvelinus namaycush in North American lakes. Environmental Biology of Fishes 83: 77-90.

Esin, E. V. \& A. E. Fedosov, 2016. The effect of chronic volcanic pollution on the morphometric characteristics of juvenile Dolly Varden (Salvelinus malma W.) on the Kamchatka peninsula. Hydrobiologia. doi:10.1007/ s10750-016-2741-7.

Finstad, A. G., T. Forseth, B. Jonsson, E. Bellier, T. Hesthagen, A. J. Jensen, D. O. Hessen \& A. Foldvik, 2011. Competitive exclusion along climate gradients: energy efficiency influences the distribution of two salmonid fishes. Global Change Biology 17: 1703-1711.

Gallagher, C. P. \& T. A. Dick, 2010. Historical and current population characteristics and subsistence harvest of Arctic char from the Sylvia Grinnell River, Nunavut, Canada, North American. Journal of Fisheries Management 30: 126-141.

Fukui, S., S. L. May-McNally, H. Katahira, S. Kitano \& I. Koizumi, 2016. Temporal change in the distribution and composition of native, introduced, and hybrid charrs in northern Japan. Hydrobiologia. doi:10.1007/s10750-0162688-8.

Hammar, J., 2014. Natural resilience in Arctic charr Salvelinus alpinus: life history, spatial and dietary alterations along gradients of interspecific interactions. Journal of Fish Biology 85: 81-118.

Hansen, M. J., B. S. Hansen \& D. A. Beauchamp, 2016a. Lake trout (Salvelinus namaycush) suppression for bull trout (Salvelinus confluentus) recovery in Flathead Lake, Montana, North America. Hydrobiologia. doi:10.1007/s10750016-2703-0.

Hansen, M. J., N. A. Nate, L. Chavarie, A. M. Muir, M. S. Zimmerman \& C. C. Krueger, 2016b. Life history differences between fat and lean morphs of lake charr (Salvelinus namaycush) in Great Slave Lake, Northwest Territories, Canada. Hydrobiologia. doi:10.1007/s10750015-2633-2.

Henriksen, E. H., R. Knudsen, R. Kristoffersen, A. M. Kuris, K. D. Lafferty, A. Siwertsson \& P.-A. Amundsen, 2016. Ontogenetic dynamics of infection with Diphyllobothrium spp. cestodes in sympatric Arctic charr Salvelinus alpinus (L.) and brown trout Salmo trutta L. Hydrobiologia. doi:10. 1007/s10750-015-2589-2.

Hooker, O. E., J. Barry, T. E. Van Leeuwen, A. Lyle, J. Newton, P. Cunningham \& C. E. Adams, 2016. Morphological, ecological and behavioural differentiation of sympatric profundal and pelagic Arctic charr (Salvelinus alpinus) in Loch Dughaill Scotland. Hydrobiologia. doi:10.1007/ s10750-015-2599-0.

Jensen, J. L. A., G. N. Christensen, K. H. Hawley, C. M. Rosten \& A. H. Rikardsen, 2016. Arctic charr exploit restricted urbanized coastal areas during marine migration: could they be in harm's way? Hydrobiologia. doi:10.1007/ s10750-016-2787-6.

Jeppesen, E., T. Mehner, I. J. Winfield, K. Kangur, J. Sarvala, D. Gerdeaux, M. Rask, H. J. Malmquist, K. Holmgren, P. Volta, S. Romo, R. Eckmann, A. Sandstrom, S. Blanco, A. Kangur, H. R. Stabo, M. Tarvainen, A. M. Ventela, M. Sondergaard, T. L. Lauridsen \& M. Meerhoff, 2012. Impacts of climate warming on the long-term dynamics of key fish species in 24 European lakes. Hydrobiologia 694: $1-39$.

Kahilainen, K. K., T. Smura, R. Knudsen, P.-A. Amundsen, M. Jokela-Määttä \& K. Donner, 2016a. Visual pigments of Arctic charr (Salvelinus alpinus (L.)) and whitefish (Coregonus lavaretus (L.)) morphs in subarctic lakes. Hydrobiologia. doi:10.1007/s10750-015-2588-3.

Kahilainen, K. K., S. M. Thomas, O. Keva, B. Hayden, R. Knudsen, A. P. Eloranta, K. Tuohiluoto, P.-A. Amundsen, T. Malinen \& A. Järvinen, 2016b. Seasonal dietary shift to zooplankton influences stable isotope ratios and total mercury concentrations in Arctic charr (Salvelinus alpinus (L.)). Hydrobiologia. doi:10.1007/s10750-016-2685-y.

Karvonen, A. \& O. Seehausen, 2012. The role of parasitism in adaptive radiations - when might parasites promote and when might they constrain ecological speciation? International Journal of Ecology 2012: 280169.

Knudsen, R., P.-A. Amundsen, A. P. Eloranta, B. Hayden, A. Siwertsson \& A. Klemetsen, 2016a. Parallel evolution of profundal Arctic charr morphs in two contrasting fish communities. Hydrobiologia. doi:10.1007/s10750-0162647-4.

Knudsen, R., K. Ø. Gjelland, A. P. Eloranta, B. Hayden, A. Siwertsson, P.-A. Amundsen \& A. Klemetsen, 2016b. A specialised cannibalistic Arctic charr morph in the piscivore guild of a subarctic lake. Hydriobiologia. doi:10.1007/ s10750-015-2601-x.

Kuhn, J. A., R. Knudsen, R. Kristoffersen, R. Primicerio \& P.-A. Amundsen, 2016. Temporal changes and between-host variation in the intestinal parasite community of Arctic charr in a subarctic lake. Hydrobiologia. doi:10.1007/ s10750-016-2731-9.

Larsson, S., T. Forseth, I. Berglund, A. J. Jensen, I. Näslund, J. M. Elliott \& B. Jonsson, 2005. Thermal adaptation of 
Arctic charr: experimental studies of growth in eleven charr populations from Sweden, Norway and Britain. Freshwater Biology 50: 353-368.

Levis, N. A. \& D. W. Pfennig, 2016. Evaluating "PlasticityFirst" evolution in nature: key criteria and empirical approaches. Trends in Ecology and Evolution XX: 1-12. doi:10.1016/j.tree.2016.03.012.

Maitland, P. S., 1995. World status and conservation of the Arctic charr Salvelinus aplinus (L.). Nordic Journal of Freshwater Research 71: 113-127.

Minns, C. K., 1992. Use of models for integrated assessment of ecosystem health. Journal of Aquatic Ecosystem Health 1: 109-118.

Miyamoto, K., 2016. Effects of body color luminance and behavioural characteristics on predation risk in salmonid fishes. Hydrobiologia. doi:10.1007/s10750-015-2573-x.

Morita, K., G. Sahashi \& J. Tsuboi, 2016. Altitudinal niche partitioning between white-spotted charr (Salvelinus leucomaenis) and masu salmon (Oncorhynchus masou) in a Japanese river. Hydrobiologia. doi:10.1007/s10750-015-2571-z.

O’Connell, M. F., J. B. Dempson \& M. Power, 2005. Spatial distributions and aspects of the biology, ecology and trophic relationships of the fishes of gander lake, a large, deep, Oligotrophic Lake in Newfoundland, Canada. International Review of Hydrobiology 90: 486-510.

Oleinik, A. G. \& L. A. Skurikhina, 2010. Mitochondrial DNA diversity and relationships of endemic charrs of the genus Salvelinus from Lake Kronotskoye (Kamchatka Peninsula). Hydrobiologia. 650: 145-159.

Power, M., J. B. Dempson, J. D. Reist, C. J. Schwarz \& G. Power, 2005. Latitudinal variation in fecundity among Arctic char populations in eastern North America. Journal of Fish Biology. 67: 255-273.

Power, M., J. D. Reist \& J. B. Dempson, 2008. Fish in highlatitude Arctic lakes. In Vincent, W. F. \& J. LaybournParry (eds), Polar Lakes and Rivers: Limnology of Arctic and Antarctic Aquatic Ecosystems. Oxford University Press, Oxford: 249-268.

Præbel, K., M. Couton, R. Knudsen \& P.-A. Amundsen, 2016. Genetic consequences of allopatric and sympatric divergence in Arctic charr (Salvelinus alpinus (L.)) from Fjellfrøsvatn as inferred by microsatellite markers. Hydrobiologia. doi:10.1007/s10750-016-2648-3.

Reist, J. D., F. J. Wrona, T. D. Prowse, M. Power, J. B. Dempson, R. J. Beamish, J. R. King, T. J. Carmichael \& C. D. Sawatzky, 2006. General effects of climate change on Arctic fishes and fish populations. Ambio 35: 370-380.

Reist, J. D., M. Power \& J. B. Dempson, 2013. Arctic charr (Salvelinus alpinus): a case study of the importance of understanding biodiversity and taxonomic issues in northern fishes. Biodiversity 14: 45-56.

Sabater, S., 2008. Alterations of the global water cycle and their effects on river structure, function and services. Freshwater Reviews 1: 75-88.

Sæther, B. S., S. I. Siikavuopio \& M. Jobling, 2016. Environmental conditions required for intensive farming of Arctic charr (Salvelinus alpinus (L.)). Hydrobiologia. doi:10. 1007/s10750-015-2572-y.
Samways, K. M., P. R. Leavitt, P. Magnan, M. A. Rodríguez \& P. R. Peres-Neto, 2015. Convergent polymorphism between stream and lake habitats: the case of brook char. Canadian Journal of Fisheries and Aquatic Sciences 72: 1406-1414.

Sánchez-Hernández, J., H.-M. Gabler \& P.-A. Amundsen, 2016. Food resource partitioning between stream-dwelling Arctic charr Salvelinus alpinus (L.), Atlantic salmon Salmo salar L. and alpine bullhead Cottus poecilopus Heckel, 1836: an example of water column segregation. Hydrobiologia. doi:10.1007/s10750-015-2547-z.

Sandlund, O. T., A. P. Eloranta, R. Borgstrøm, T. Hesthagen, S. I. Johnsen, J. Museth \& S. Rognerud, 2016. The trophic niche of Arctic charr in large southern Scandinavian lakes is determined by fish community and lake morphometry. Hydrobiologia. doi:10.1007/s10750-016-2646-5.

Santaquiteria, A., M.-A. Svenning \& K. Præbel, 2016. Contrasting levels of strays and contemporary gene flow among anadromous populations of Arctic charr, Salvelinus alpinus (L.), in northern Norway. Hydrobiologia. doi:10.1007/ s10750-016-2905-5.

Siikavuopio, S. I., B. S. Sæther, H. Johnsen, T. Evensen \& R. Knudsen, 2014. Temperature preference of juvenile Arctic charr originating from different thermal environments. Aquatic Ecology 48: 313-320.

Siwertsson, A., B. Refsnes, A. Frainer, P.-A. Amundsen \& R. Knudsen, 2016. Divergence and parallelism of parasite infections in Arctic charr morphs from deep and shallow lake habitats. Hydrobiologia. doi:10.1007/s10750-0152563-z.

Svenning, M.-A., K. Sandem, M. Halvorsen, Ø. KanstadHanssen, M. Falkegård \& R. Borgstrøm, 2016. Change in relative abundance of Atlantic salmon and Arctic charr in Veidnes River, Northern Norway: a possible effect of climate change? Hydrobiologia. doi:10.1007/s10750-0162690-1.

Taylor, E. B., 2016. The Arctic char (Salvelinus alpinus) "complex" in North America revisited. Hydrobiologia. doi:10.1007/s10750-015-2613-6.

Tran, L., J. D. Reist \& M. Power, 2016. Northern Dolly Varden charr total mercury concentrations: variation by life-history type. Hydrobiologia. doi:10.1007/s10750-016-2666-1.

van der Velden, S., J. B. Dempson, M. S. Evans, D. C. G. Muir \& M. Power, 2013. Basal mercury concentrations and biomagnification rates in freshwater and marine food webs: effects on Arctic charr (Salvelinus alpinus) from eastern Canada. Science of the Total Environment 444: 531-542.

van der Velden, S., J. B. Dempson \& M. Power, 2015. Comparing mercury concentrations across a thirty year time span in anadromous and non-anadromous Arctic charr from Labrador, Canada. Science of the Total Environment 509: 165-174.

Winfield, I. J., J. Hateley \& J. M. Fletcher, 2010. Population trends of Arctic charr (Salvelinus alpinus) in the UK: assessing the evidence for a widespread decline in response to climate change. Hydrobiologia 650: 55-65. 